ORIGINAL ARTICLE

\title{
Prediction of Preterm Delivery in Pregnant Women with Threatened Preterm Labor Using Transvaginal Ultrasound and Neutrophils to Lymphocytes Ratio
}

\author{
Ali Elshabrawy Ali ${ }^{1}$, Safaa Abd-Elsalam Ibrahim ${ }^{1}$, Mostafa Ahmed Abdo ${ }^{1}$, Soad Fathi Kareem ${ }^{2} *$ \\ ${ }^{I}$ Department of Obstetrics and Gynecology, Faculty of Medicine-Zagazig University, Egypt. \\ ${ }^{2}$ Department of Obstetrics and Gynecology, Faculty of Medicine, Zliten teaching hospital (Zliten - Libya .
}

\section{*Corresponding author:}

Name: Soad Fathi Kareem

\section{Email:}

\section{soadkaream84@gmail.com}

\begin{tabular}{|l|l|}
\hline Submit Date & $2019-04-01$ \\
\hline Revise Date & $2019-07-09$ \\
\hline Accept Date & $2019-07-13$ \\
\hline
\end{tabular}

\begin{abstract}
Background: Preterm labor is defined as regular contractions of the uterus resulting in changes in the cervix that start before 37 weeks of pregnancy. It contributes directly to estimated one million neonatal deaths annually and is a significant contributor to childhood morbidity. Prediction of preterm labor could contribute to reduction in neonatal morbidity and mortality. Aim of the work: The aim of this study is to compare the level of neutrophil/leucocyte ratio (NLR) and C-reactive protein (CRP) between preterm and term patients and to show whether those inflammatory markers either alone or in combination with cervical length via transvaginal ultrasound are useful for prediction of spontaneous preterm delivery in patients with threatened preterm labor. Patients and methods: This is a prospective study that was conducted at Zagazig University Hospitals. It included 90 women, 60 with threatened preterm labor, and 30 healthy pregnant women at term. Results: Markers combination (neutrophil/leucocyte ratio (NLR), C-reactive protein (CRP) and cervical length by transvaginal sonography) is the best predictor for preterm labor in patients with threatened preterm labor with sensitivity and specificity (94.7 and 86.7; respectively) with high accuracy (95.5\%). Conclusion: Findings of this study demonstrated that the combined marker is more sensitive $\&$ specific for predicting spontaneous preterm delivery in pregnant women with threatened preterm labor in comparison with cervix length, NLR, CRP alone. The combined marker is cost-effective test as it is based on leucocyte counts \& cervical length which already investigated in patients with threatened preterm labor.

Key words: preterm labor; C-reactive protein; neutrophil/leucocyte ratio; cervical length
\end{abstract}

\section{INTRODUCTION}

P reterm birth, defined as delivery before 37 completed weeks, with an annual incidence of $9-15 \%$, is implicated in approximately two thirds of perinatal mortality worldwide. Preterm births are also associated with neonatal death \& with immediate \& long-term morbidities, making this a major public health issue. For these reasons, many researchers are working to understand mechanisms of preterm birth \& testing interventions to reduce its occurrence [1].

Currently, over $60 \%$ of preterm deliveries are unexplained [2], ascribable only to 'idiopathic' preterm labor or preterm premature rupture of fetal membranes. Some experts believe that these are associated with a subclinical inflammatory response in the maternal \&/or fetal tissues [3].

Furthermore, there is emerging evidence that physiological parturition is associated with up-regulation of inflammatory pathways. Labor at term is associated with a massive influx of leukocytes especially neutrophils into the myometrium \& cervix. Leukocyte migration during parturition appears to be actively promoted by factors released by the myometrium \& cervix during labor\& culminates in tissue leukocytes which are 
major producers of the inflammatory cytokines [4].

A role for the pro-inflammatory cytokines is evident in term \& preterm delivery, \& this is independent of the presence of infection [5].

The mechanism responsible for lymphocytopenia is induced by several factors including hormones, chemokines \& cytokines, which regulate the number\& activity of the lymphocyte \& show the intensity of inflammation as well as the resistance \& adaptability of the immune system [3].

In contrast, neutrophilia is caused by delayed apoptosis of neutrophils \& stimulation of stem cells by growing factors (GCSF) [6].

Recently, the diagnostic role of the neutrophil to lymphocyte ratio (NLR) \& Creactive protein (CRP) have been investigated in various diseases including preterm labor [4].

In a clinical setting, accurate diagnosis of preterm labor is essential, to allow timely transfer to perinatal centers \& to make informed decisions about the use of antenatal steroids \& tocolytics, which can be associated with serious adverse events, in order to limit their use to cases in which they are clearly needed [7].

Cervical length, as measured by transvaginal ultrasonography, has been shown to predict preterm birth in asymptomatic lowrisk women as well as those presenting with threatened preterm labor [8].

Although the current recommendation is to combine transvaginal ultrasound measurement of cervix length and cervicovaginal fetal fibronectin for the prediction of preterm delivery, more simple and sensitive methods are always needed [9].

The aim of this study is to compare the level of neutrophil/leucocyte ratio (NLR) and C-reactive protein (CRP) between preterm and term patients and to show whether those inflammatory markers either alone or in combination with cervical length via transvaginal ultrasound are useful for prediction of spontaneous preterm delivery in patients with threatened preterm labor.

\section{Patients and Methods:}

This is a prospective study that was conducted at Zagazig University hospital from September 2018 to February 2019. It included 90 women, 60 with threatened preterm labor, and 30 healthy pregnant women at term from the outpatient clinic and inpatient department.

Written informed consent was obtained from all participants and the study was approved by the research ethical committee of the department and the faculty of medicine, Zagazig University. The work has been carried out in accordance with The Code of Ethics of the World Medical Association (Declaration of Helsinki ) for studies involving humans.

The study population included two groups;

Group I: (study group) included 60 pregnant women with threatened preterm labor, subdivided into two subgroups:

Group Ia: women who deliver before 37 weeks in spite of tocolytics.

Group Ib: women who complete their pregnancy up to term.

Group II: (Control group) included 30

healthy pregnant women at term.

\section{Inclusion criteria}

- Singleton gestation.

- $\quad$ Gestational age from 24-36 weeks+6 days.

- Cervical dilatation $<3 \mathrm{~cm}$ by digital examination.

- The absence of a major uterine anomaly.

- Intact membranes

- The absence of maternal or placental diseases.

- Temperature $<38 \mathrm{C}$ or the absence of fetal tachycardia.

- Women with a history at least one spontaneous late miscarriage or preterm labor before 36 weeks +6 days.

- Criteria of threatened preterm labor as four or more uterine contractions in one hour, vaginal bleeding, abdominal or back pain.

- No history of prior or present cerclage. Exclusion criteria 
- Established preterm labor.

- Any factor that would affect cervical length as previous cervical trauma.

- Any factors affecting studied serum markers as infection and blood diseases.

- Temperature $>38 \mathrm{C}$ or the presence of fetal tachycardia.

- Multi fetal gestation.

- The presence of maternal or placental diseases that may alter immune response including any infective and or inflammatory process, DM, pregnancy induced hypertention, placenta previa and abruption.

- Major uterine and fetal anomalies.

Patients in the study subjected to the following:

a- Cervical length measurement to all patients with the diagnosis of preterm labor and intact membranes.

b- NLR is the absolute neutrophil count divided by the absolute lymphocyte count.

c- CRP level in sera obtained at admission.

d- Combined markers were obtained by dividing cervical length by NLR.

Antenatal corticosteroid administration (dexamethasone $6 \mathrm{mg}$ IM every 12 hours for 4 doses) was initiated for women between 24 and 34 weeks of gestation who were at risk of preterm delivery within 7 days. For all study subjects, if preterm labor did not improve with bed rest and hydration, tocolysis was started with calcium channel blockers (nifedipine was given initially $10 \mathrm{mg}$ orally/15-30 minutes for 3 doses then $10 \mathrm{mg}$ orally/6hours) after admission

According to pregnancy outcome, patients diagnosed with preterm labor were divided into two groups:

- Group 1: Preterm delivery group.

- Group 2: Term delivery group

Secondary outcome is related to fetal condition and rate of complication.

\section{Statistical analysis:}

Data collected throughout history, basic clinical examination, laboratory investigations and outcome measures coded, entered and analyzed using Microsoft Excel software.
Data were then imported into Statistical Package for the Social Sciences (SPSS version 20.0) (Statistical Package for the Social Sciences) software for analysis. P value was set at $<0.05$ for significant results $\&<0.001$ for high significant result.

\section{Results:}

This study included 90 patients divided into 3 groups, the $1^{\text {st }}$ group (A) was control pregnant term group consisted of 30 women, $2^{\text {nd }}$ group (B) was threatened preterm group and they had term labor and consisted of 30 women and the $3^{\text {rd }}$ group (C) was threatened preterm group and they had preterm labor and also consisted of 30 women. Comparing patients' clinical characteristics between the three studied groups was shown in table (1).

Table (2) shows that there was statistically significant difference between the three studied groups in neutrophils count and lymphocytes count (group $\mathrm{C}$ had increased neutrophils and decreased lymphocytes than group A \& B). But regarding $\mathrm{Hb}$, there was no statistically significant difference between the three studied groups.

Table (3) shows that there was statistically significant difference between the term delivery women (groups A \& B) and the preterm delivery women (group C) in cervical length, neutrophils lymphocytes ratio (NLR) and CRP (the preterm delivery women had increased neutrophils lymphocytes ratio and CRP than the term delivery ones).

The results derived from the ROC curve showed that cut off value of NLR $\leq 4.8$ at this point sensitivity and specificity (91.3 and 90.4; respectively) as shown in table (4).

The results derived from the ROC curve showed that cut off value of CRP $>6.5$ at this point sensitivity and specificity (76.0 and 60.0; respectively) as shown in table (5).

The results derived from the ROC curve showed that cut off value of cervical length $>2.3$ at this point sensitivity and specificity (93.8 and 94.0; respectively) as shown in table (6).

The results derived from the ROC curve showed that markers combination is the best predictor factor for preterm labor with sensitivity and specificity (94.7 and 86.7; respectively) with high accuracy (95.5\%) as shown in table 
Ali E. et al....

Zagazig University Medical Journal

Table (1): Comparing patients' clinical characteristics between the three studied groups:

\begin{tabular}{|c|c|c|c|c|c|}
\hline Variable & $\begin{array}{l}\text { Group A(30) } \\
\text { mean } \pm \text { SD } \\
\text { Range }\end{array}$ & $\begin{array}{l}\text { Group B(30) } \\
\text { mean } \pm \text { SD } \\
\text { Range }\end{array}$ & $\begin{array}{l}\text { Group C (30) } \\
\text { mean } \pm \text { SD } \\
\text { Range }\end{array}$ & F-test & P-value \\
\hline Age & $\begin{array}{l}24.9 \pm 4.3 \\
(19-32)\end{array}$ & $\begin{array}{l}25.1 \pm 4.7 \\
(18-32)\end{array}$ & $\begin{array}{l}26 \pm 6.2 \\
(19-37)\end{array}$ & 0.4 & 0.6 \\
\hline BMI & $\begin{array}{l}27.6 \pm 2.4 \\
(23-30.4)\end{array}$ & $\begin{array}{l}26.4 \pm 2.4 \\
(23.4-30.9)\end{array}$ & $\begin{array}{l}26 \pm 6.2 \\
(23.1-37.2)\end{array}$ & 2.8 & 0.06 \\
\hline GA at examination & $\begin{array}{l}38.3 \pm 0.5 \\
(37-39)\end{array}$ & $\begin{array}{l}37.2 \pm 0.6 \\
(36-38)\end{array}$ & $\begin{array}{l}31.1 \pm 1.7 * \\
(28-33)\end{array}$ & 51.8 & $0.001 * *$ \\
\hline GA at delivery & $\begin{array}{l}39.1 \pm 0.4 \\
(38-40)\end{array}$ & $\begin{array}{l}37.5 \pm 0.5 \\
(38-39)\end{array}$ & $\begin{array}{l}32.7 \pm 1.3^{*} \\
(30-34)\end{array}$ & 89.5 & $0.001 * *$ \\
\hline $\begin{array}{l}\text { Gravidity } \\
\text { Primigravida(20) } \\
\text { G2-3 (37) } \\
\text { G4 and more(33) }\end{array}$ & $\begin{array}{l}20.0 \\
40.0 \\
40.0\end{array}$ & $\begin{array}{l}23.3 \\
46.7 \\
30.0\end{array}$ & $\begin{array}{lr}7 & 25 \\
11 & 36.7 \\
12 & 40.0\end{array}$ & 1.02 & 0.9 \\
\hline $\begin{array}{l}\text { Parity } \\
\text { Nulliparous (20) } \\
\text { P1-3 (51) } \\
\text { P3 and more (19) }\end{array}$ & $\begin{array}{c}20.0 \\
56.7 \\
23.3\end{array}$ & $\begin{array}{l}23.3 \\
66.7 \\
10.0\end{array}$ & $\begin{array}{ll}7 & 23.3 \\
14 & 46.7 \\
9 & 30.0\end{array}$ & 4.1 & 0.3 \\
\hline
\end{tabular}

**Statistically highly significant difference $(\mathrm{P} \leq 0.001)$

Table (2): Comparing CBC between the three studied groups:

\begin{tabular}{|l|l|l|l|l|l|}
\hline & $\begin{array}{l}\text { Group A(30) } \\
\text { mean } \pm \text { SD } \\
\text { Range }\end{array}$ & $\begin{array}{l}\text { Group B(30) } \\
\text { mean } \pm \text { SD } \\
\text { Range }\end{array}$ & $\begin{array}{l}\text { Group C (30) } \\
\text { mean } \pm \text { SD } \\
\text { Range }\end{array}$ & F-test & P-value \\
\hline Hb & $\begin{array}{l}10.7 \pm 1.3 \\
(9.2-13)\end{array}$ & $\begin{array}{l}11.1 \pm 0.7 \\
(9.7-12.1)\end{array}$ & $\begin{array}{l}10.9 \pm 1.2 \\
(9.4-13.1)\end{array}$ & 0.7 & 0.4 \\
\hline $\begin{array}{l}\text { Neutrophils } \\
\text { count }\end{array}$ & $\begin{array}{l}7.05 \pm 0.4 \\
(5.2-8.9)\end{array}$ & $\begin{array}{l}6.6 \pm 0.5 \\
(2.8-9.2)\end{array}$ & $\begin{array}{l}7.9 \pm 1.11^{*} \\
(5.2-9.3)\end{array}$ & 6.3 & $\mathbf{0 . 0 0 3 *}$ \\
\hline $\begin{array}{l}\text { Lymphocytes } \\
\text { count }\end{array}$ & $\begin{array}{l}1.5 \pm 0.2 \\
(1.1-2.3)\end{array}$ & $\begin{array}{l}1.55 \pm 0.3 \\
(1.1-2.2)\end{array}$ & $\begin{array}{l}1.28 \pm 0.2 * \\
(1.1-2.0)\end{array}$ & 8.6 & $\mathbf{0 . 0 0 1 * *}$ \\
\hline
\end{tabular}

*Statistically significant difference $(P \leq \mathbf{0 . 0 5})$

$* *$ Statistically highly significant difference $(\mathrm{P} \leq \mathbf{0 . 0 0 1})$ 
Table (3): Comparing NLR, CRP and cervical length between the preterm and term groups:

\begin{tabular}{|l|l|l|l|l|}
\hline Variable & $\begin{array}{l}\text { Term }(\mathbf{6 0}) \\
\text { mean } \pm \text { SD } \\
\text { Range }\end{array}$ & $\begin{array}{l}\text { preterm(30) } \\
\text { mean } \pm \text { SD } \\
\text { Range }\end{array}$ & t-test & P-value \\
\hline $\boldsymbol{N L R}$ & $\begin{array}{l}4.55 \pm 1.14 \\
(2.3-7.9)\end{array}$ & $\begin{array}{l}6.3 \pm 1.5 \\
(3.3-8.4)\end{array}$ & 6.2 & $\mathbf{0 . 0 0 1 * *}$ \\
\hline $\boldsymbol{C R P}$ & $\begin{array}{l}6.88 \pm 3.9 \\
(0.9-29)\end{array}$ & $\begin{array}{l}16.3 \pm 9.6 \\
(1-49)\end{array}$ & $\begin{array}{l}\text { Mann- } \\
\text { witenny } \\
4.8\end{array}$ & $\mathbf{0 . 0 0 1 * *}$ \\
\hline cervical length & $\begin{array}{l}3.77 \pm 0.61 \\
(2.7-4.9)\end{array}$ & $\begin{array}{l}2.04 \pm 0.5 \\
(1.6-3.5)\end{array}$ & 13.2 & $\mathbf{0 . 0 0 1 * *}$ \\
\hline
\end{tabular}

**Statistically highly significant difference $(\mathbf{P} \leq \mathbf{0 . 0 0 1})$

Table (4): The predictive ability of NLR in detection of preterm delivery:

\begin{tabular}{|l|l|l|l|l|l|}
\hline Variable & Sensitivity & Specificity & PVP & PVN & Accuracy \\
\hline NLR & $91.3 \%$ & $90.4 \%$ & $89.9 \%$ & $90.6 \%$ & $90.0 \%$ \\
\hline
\end{tabular}

Table (5): The predictive ability of CRP in detection of preterm delivery:

\begin{tabular}{|l|l|l|l|l|l|}
\hline Variable & Sensitivity & Specificity & PVP & PVN & Accuracy \\
\hline $\boldsymbol{C R P}$ & $76.0 \%$ & $60.0 \%$ & $68.5 \%$ & $70 \%$ & $73.0 \%$ \\
\hline
\end{tabular}

Table (6): The predictive ability of cervical length in detection of preterm delivery:

\begin{tabular}{|l|l|l|l|l|l|}
\hline Variable & Sensitivity & Specificity & PVP & PVN & Accuracy \\
\hline Cervical length & $93.8 \%$ & $94.0 \%$ & $85.4 \%$ & $95.0 \%$ & $93.0 \%$ \\
\hline
\end{tabular}

Table (7): The predictive ability of marker combination in detection of preterm delivery:

\begin{tabular}{|l|l|l|l|l|l|}
\hline Variable & Sensitivity & Specificity & PVP & PVN & Accuracy \\
\hline $\begin{array}{l}\text { Markers combination (NLR, } \\
\text { CRP and cervical length) }\end{array}$ & $94.3 \%$ & $86.7 \%$ & $87.3 \%$ & $98.3 \%$ & $95.5 \%$ \\
\hline
\end{tabular}



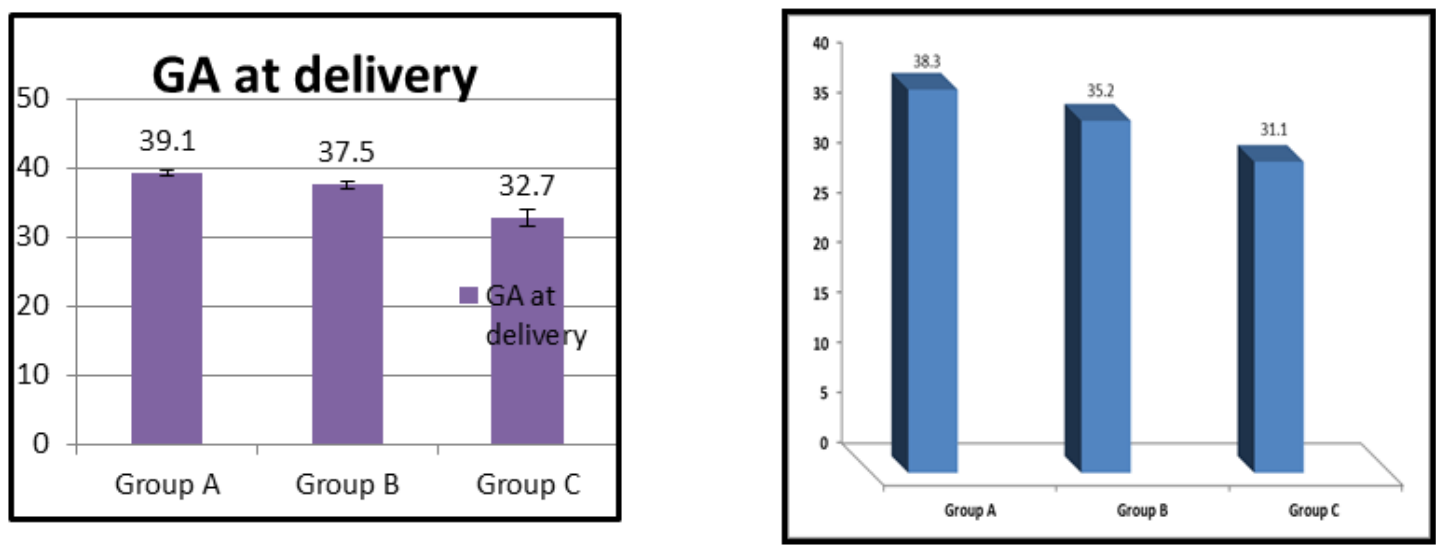

Figure 1: Bar charts for comparing gestational age at examination at time of delivery between the three studied groups

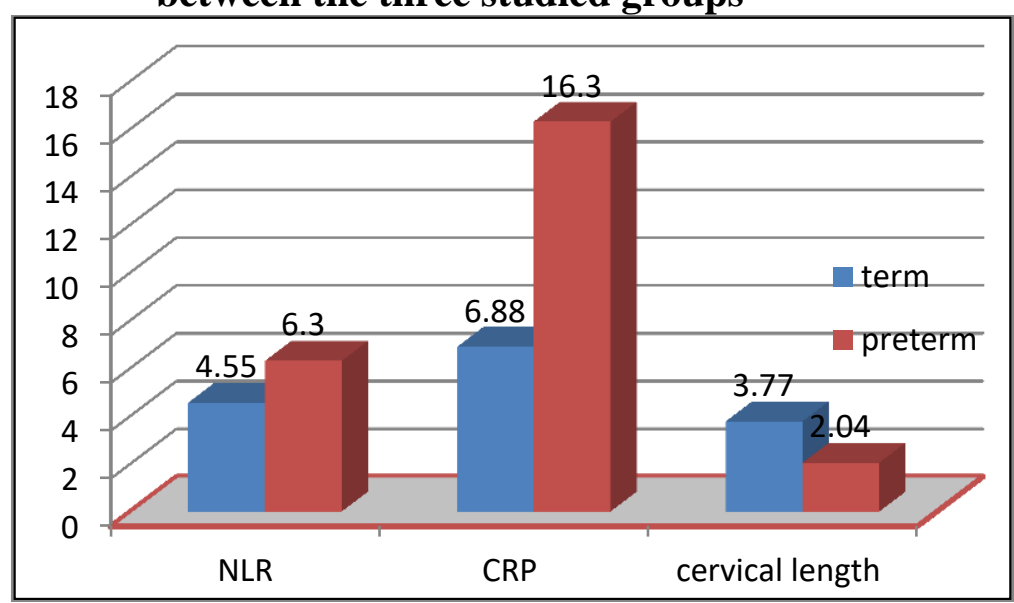

Figure2: Bar chart for comparing NLR, CRP and cervical lengthbetween thepreterm and term group

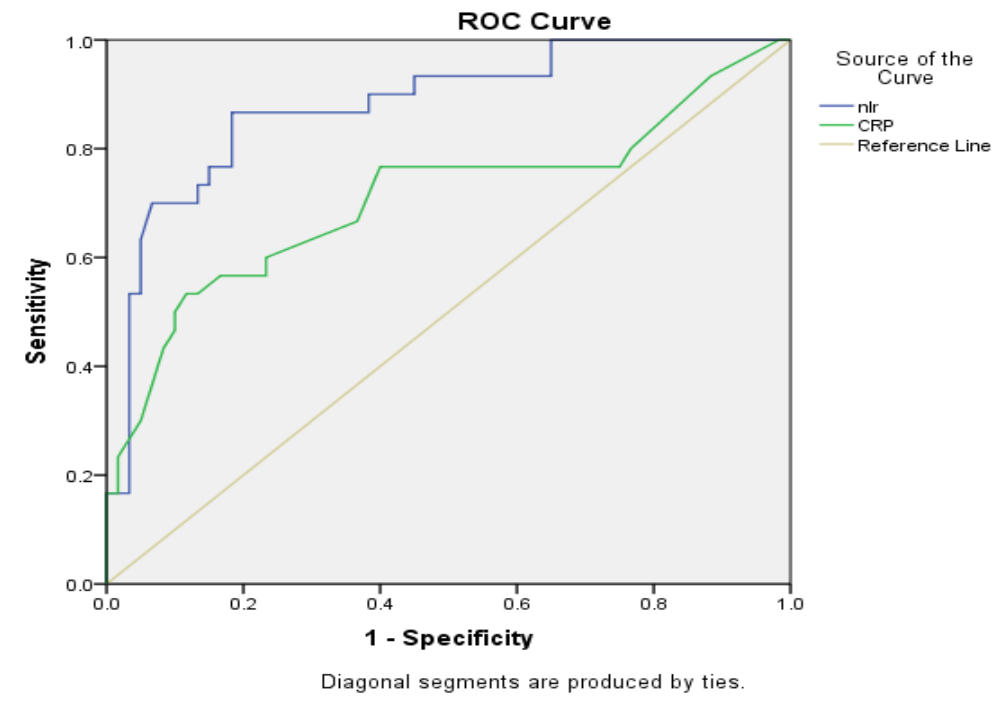

DISCUSSION

Defined as delivery before completing 37 weeks of gestation, preterm birth (PB) is caused by multiple etiologies as individual and environmental factors, which makes the prediction and prevention of $\mathrm{PB}$ a challenging process in antenatal care. Preterm birth (PB) is an important subject for being one of the leading causes of neonatal mortality and its long term neurologic and developmental problems. It is related with cerebral palsy, bronchopulmonary dysplasia, retinopathy of prematurity, and much other morbidity that come with the prematurity [10] In 2010, 
there were 15 million preterm births $(<37$ weeks' gestation) worldwide, with a prevalence of $5-18 \%$ of live births [11]. In 2015, PB rate in United States was $9.62 \%$ among 3,977,745 births which meant significant number of neonates needed further medical care [12]. PB is a complex condition resulting from multiple etiologic pathways [13]. PB may be iatrogenic due to medical interventions for maternal and fetal indications, whereas $80 \%$ of PB occurs spontaneously; and while 1 million children die because of prematurity, more survive the consequences of PB [14].

The aim of this work is improvement of fetal outcome by early prediction of preterm birth in pregnant women presented by threatened preterm labor.

Recently, the diagnostic role of the neutrophil to lymphocyte ratio (NLR) \& Creactive protein (CRP) have been investigated in various diseases including preterm labor. CRP is an acute-phase protein mainly synthesized by the liver in response to some cytokines. They are potentially useful to diagnosing infection \& monitoring different clinical conditions it is also altered during pregnancy, labor, \& postpartum in normal conditions \& disease [15].

Transvaginal sonographic measurement of cervical length has been shown to be an objective, reproducible \& reliable method to predict preterm delivery in high risk pregnancies, however it has low sensitivity \& specificity. The selective use of fetal fibronectin detection after cervical length measurement has been found to be more specific than cervical length alone in predicting the risk of spontaneous preterm delivery in threatened preterm labor Although, negative fetal fibronectin are able to stratify females who will not deliver prematurely after the onset of symptoms, a positive test is only a moderate predictor of spontaneous labor before 37 weeks of gestation [16].

Combination of neutrophil/ lymphocyte ratio, CRP and cervical length measurement by transvaginal ultrasound was evaluated in our study for better prediction of preterm birth in pregnant women with threatened preterm labor.

Our study revealed that patients with threatened preterm labor who delivered before 37 weeks have relative neutrophilia, lymphocytopenia \& increased NLR as compared to those who delivered $\geq 37$ weeks. These findings were consistent with Romero et al [17]. Our data also showed that neutrophil counts increased \& lymphocyte counts decreased; with significantly increased NLR in patients with labor at term confirming that inflammatory mediators play a crucial role in human parturition. These findings were in agreement with Yuan et al [18].

In our research the mean CPR is found to be significantly higher at term in laboring women than those who were not in labor, in consistence with Luciane et al [19]. We also found that the CRP was significantly higher in patients who had spontaneous preterm delivery $<37$ weeks than those who delivered $\geq 37$ weeks, this goes with Min-A Kim et al [20].

In our study, the diagnostic value of NLR in the prediction of preterm delivery in patient with threatened preterm labor was highly promising with sensitivity, specificity, PPV, NPV and accuracy: 91.3\%, 90.4\%, $89.9 \%, 90.6 \%$ and $90 \%$ respectively.

In our research, the diagnostic value of CRP in the prediction of preterm delivery in patient with threatened preterm labor was less promising when compared to NLR with sensitivity, specificity, PPV, NPV and accuracy: $76.0 \%, 60.0 \%, 68.5 \%, 70 \%$ and $73.0 \%$ respectively.

In women with threatened preterm labor, sonographic measurement of cervical length helps distinguish between true $\&$ false labor \& there is an inverse correlation between cervical length \& the frequency of preterm delivery [20] .

In our study, the diagnostic value of cervical length measurement by transvaginal ultrasound in the prediction of preterm delivery in patient with threatened preterm labor was highly promising with sensitivity, specificity, PPV, NPV and accuracy: $93.8 \%$, $94.0 \%, \quad 85.4 \%, \quad 95.0 \%$ and $93.0 \%$ respectively. These figures were better than the ranges found by the previous study by 
Min-A Kim et al [20].

In a study by Amal et al., 2015, transvaginal sonographic cervix length measurement provides a method for predicting spontaneous preterm delivery $<37$ weeks in patients with threatened preterm labor with sensitivity \& specificity of $60 \%$ \& $79 \%$ respectively [21].

As no single biomarker has yet been shown to fulfill all the requirements of a clinically reliable predictive test for spontaneous preterm birth, multiple-marker tests based on combinations of several independent markers or adding their results to cervical length test results may enhance our ability to predict spontaneous preterm birth. The combined marker obtained by dividing cervix length by NLR, has been suggested as a simple novel marker for spontaneous preterm delivery in patients with threatened preterm labor [21].

In our research, the diagnostic value of the combined use of the three markers (NLR, $\mathrm{CRP}$ and cervical length measurement by transvaginal ultrasound) in the prediction of preterm delivery in patient with threatened preterm labor was highly promising when compared to single marker use with sensitivity, specificity, PPV, NPV and accuracy: $94.3 \%, 86.7 \%, 87.3 \%, 98.3 \%$ and $95.5 \%$ respectively.

In a study by Amal et al., 2015, the combined marker was significantly higher in patients who delivered $<37$ weeks than those who delivered $\geq 37$ weeks of gestation. When compared to cervix length or NLR alone, the combined marker has the highest AUC 0.832 (95\% CI: 0.748-0.899) with sensitivity of $65 \%$ \& specificity of $87 \%$ at a cut-off value of 0.29 . These results indicate that the combined marker has better diagnostic value for patients with preterm delivery than cervix length or NLR alone [21].. This finding was supported by Min-A Kim et al [20].

Threshold of cervical length in 24 weeks of gestation for PB risk was defined as $25 \mathrm{~mm}$ (10th percentile), with $37.3 \%$ sensitivity and 92.2\% specificity. A meta-analysis showed that the knowledge of cervical length had a reduced risk for PB before 37 weeks. A recent study in an extensive population reported that universal cervical screening program during mid-trimester sonogram in women without a history of preterm birth was associated with reduction in the $\mathrm{PB}$ [22].

Within 3-week period, a shortening in cervical length $>10 \%$ was found associated with increased risk of PB. Among women with threatened preterm labor, cervical length was assessed in women with and without cervical dilatation. It was reported that risk for PB was higher in women with cervical dilatation, while short cervical length was independently associated with preterm birth. A cervical length $\leq 15 \mathrm{~mm}$ was reported as the most optimal cut-off with $81 \%$ specificity and $83 \%$ positive predictive value for predicting the true preterm labor [22]. In our study cervical length more than $2.3 \mathrm{~cm}$ is usually associated with full term delivery.

In a study by Chu et al they randomly selected patients delivered before 37 weeks (PT) and patients that delivered at term (T) during the last 10 years. Only patients in active labor were included. We compared their N/L Ratio at the time of admission to Labor and Delivery. We excluded individuals with known infection, inflammatory diseases, and hematological disorders, as well all those that received steroids at least 3 weeks prior to determining their N/L ratio. They found that $\mathrm{N} / \mathrm{L}$ ratio was significantly elevated in preterm patients compared to those delivered at term (PT $5.9 \pm 5.1 ; \mathrm{T} 4.7 \pm 3.2, \mathrm{p}=0.007$ ) and concluded that $\mathrm{N} / \mathrm{L}$ ratio appears to be elevated in preterm delivery. The clinical utility warrants further study [4].

Fuchs et al showed that a cervical length of $<15 \mathrm{~mm}$ in a population presenting with painful contractions $(<32$ weeks) had a 5.5fold increased risk (44\%) of delivery within a week, and those with a cervical length of $\geq 15$ $\mathrm{mm}$ had a $2 \%$ risk. In other studies, delivery occurred within 7 days of presentation in $37 \%$ of 43 women with cervical length $<15 \mathrm{~mm}$, and a cervical length of $<20 \mathrm{~mm}$ had a $93.7 \%$ and $87.5 \%$ positive predictive value for preterm birth in primiparous and multiparous women respectively [23].

In 2010, Sotiriadis et al published a metaanalysis on the use of cervical length measurements in patients presenting with 
symptoms of preterm labor. They included prospective cohort and/or case-control studies that evaluated transvaginal ultrasonographic assessment of cervical length for the prediction of preterm birth in women with a singleton pregnancy and intact membranes (studies with $<20 \%$ premature rupture of membranes and multiples were included, however Studies involving the use of tocolytics and/or prophylactic steroid administration were also included. They used a weighted analysis to determine test performance. The cumulative data suggest that the cervical length measurement in symptomatic women can be used to discriminate between those at higher and those at lower risk of preterm delivery, which may help to rationalize their management; however, there was considerable heterogeneity across the studies. On the basis of the weighted estimates, and using a pooled prevalence of $11.1 \%$ for birth within 1 week of presentation, Sotiriadis et al calculated that the negative predictive values of $15 \mathrm{~mm}, 20$ $\mathrm{mm}$, and $25 \mathrm{~mm}$ would be $94.8 \%, 96.3 \%$, and $95.8 \%$, respectively [24]

In a study by Hiersch et al overall, 1068 women with threatened preterm labor met the inclusion criteria; of them, $276(25.8 \%)$ had cervical dilatation, and $792(74.2 \%)$ had a closed cervix. The risk of preterm delivery before 37 weeks was significantly higher in the cervical dilatation group than the closed cervix group, as well as a shorter assessmentto- delivery interval of within 14 days $(\mathrm{P}=$ .001 and .004, respectively). On a multivariable analysis, cervical length was independently associated with the risk of preterm delivery in both groups. There was no significant difference between women with cervical dilatation and those with a closed cervix regarding the area under the receiver operating characteristic curves of cervical length for prediction of preterm delivery before $37(0.674$ versus $0.618 ; \mathrm{P}=.18)$ and 34 ( 0.628 versus $0.640 ; \mathrm{P}=.88)$ weeks and an assessment-to-delivery interval of 14 days ( 0.686 versus $0.660 ; \mathrm{P}=.72$ ). The negative predictive value of cervical length ranged from $77.4 \%$ to $95.7 \%$ depending on the different thresholds used. They concluded that cervical length is significantly associated with the risk of preterm delivery and the interval from examination to delivery in women with a closed cervix and can also be used in those with cervical dilatation presenting with threatened preterm labor. The main advantage of cervical length measurement in this setting is its relatively high negative predictive value. However, the predictive accuracy of cervical length as a single measure is relatively limited. Thus, more efforts should be directed at developing additional diagnostic tools that will improve our ability to predict the risk of preterm delivery [25]

\section{CONCLUSION}

Findings of this study demonstrated that the combined marker is more sensitive \& specific for predicting spontaneous preterm delivery in pregnant women with threatened preterm labor in comparison with cervix length, NLR, CRP alone. The combined marker is cost-effective test as it is based on leucocyte counts \& cervical length which already investigated in patients with threatened preterm labor. However, this observation needs further studies to assess these biologic markers as predictor.

\section{Acknowledgments:}

The authors would like to thank all the staff members of Obstetrics and Gynecology Department, Faculty of Medicine, Zagazig University who helped us to complete this work. Also authors are very grateful to all included women for their valuable contribution in this work.

Conflict of interest: No conflict of interest. Funding process: No funding.

\section{REFERENCES}

(1) Committee on Practice Bulletins .Obstetrics, the American College of Obstetricians and Gynecologists. Practice bulletin no. 130: prediction and prevention of preterm birth. Obstet Gynecol. 2012; 120: 964.

(2) Koullali B, Oudijk MA, Nijman TA, Mol BW, Pajkrt E. Risk assessment and management to prevent preterm birth. InSeminars in Fetal and Neonatal Medicine 2016 ;. 21(2): 80-88 .

(3) Morgan MA, Goldenberg RL, Schulkin J. Obstetrician-gynecologists' practices regarding preterm birth at the limit of viability. The Journal of Maternal-Fetal \& Neonatal Medicine. 2008; 21(2):115-21.

(4) Lam MC, Hunt J, Anasti J. Neutophil to Lymphocyte Ratio: A Marker for Preterm 
Labor?[21R]. Obstetrics \& Gynecology. 2017;129(5):188-9.

(5) Vogel I, Thorsen P, Curry A, Sandager P, Uldbjerg $\mathbf{N}$. Biomarkers for the prediction of preterm delivery. Acta obstetricia et gynecologica Scandinavica. 2005;84(6):516-25.

(6) Kim MA, Lee BS, Park YW, Seo K. Serum markers for prediction of spontaneous preterm delivery in preterm labour. European journal of clinical investigation. 2011;41(7):773-80.

(7) de Carvalho MH, Bittar RE, de Lourdes Brizot M, Bicudo C, Zugaib M. Prediction of preterm delivery in the second trimester. Obstetrics \& Gynecology. 2005 ;105(3):532-6.

(8) Berghella V, Owen J, MacPherson C, Yost N, Swain M, Dildy GA, et al. Natural history of cervical funneling in women at high risk for spontaneous preterm birth. Obstetrics \& Gynecology. 2007;109(4):863-9.

(9) Welsh A, Nicolaides K.. Cervical screening for preterm delivery. Current Opinion in Obstetrics and Gynecology. 2002;1;14(2):195-202

(10) . Blencowe H, Cousens S, Oestergaard MZ, Chou D, Moller AB, Narwal R, et al. National, regional, and worldwide estimates of preterm birth rates in the year 2010 with time trends since 1990 for selected countries: a systematic analysis and implications. The lancet. 2012 ;379(9832):2162-72.

(11) Torchin H, Ancel PY. Epidemiology and risk factors of preterm birth. Journal de gynecologie, obstetrique et biologie de la reproduction. 2016 ;45(10):1213-30.

(12) Hamilton BE, Martin JA, Osterman MJ. Births: preliminary data for 2015. Natl Vital Stat Rep 2016; 65(3): 1-15.

(13) Frey HA, Klebanoff MA. The epidemiology, etiology, and costs of preterm birth. InSeminars in Fetal and Neonatal Medicine 2016; 21(2): 68-73.

(14) WHO, "Preterm birth 2016 [updated November 201624/3/ 2017]," http://www.who.int/mediacentre/factsheets/fs363/ en/

(15) Cho H, Hur HW, Kim SW, Kim SH, Kim JH, Kim YT, et al. Pre-treatment neutrophil to lymphocyte ratio is elevated in epithelial ovarian cancer and predicts survival after treatment. Cancer immunology, immunotherapy. 2009 ;58(1):15-23.

(16) To MS, Skentou CA, Royston P, Yu CK, Nicolaides KH. Prediction of patient-specific risk of early preterm delivery using maternal history and sonographic measurement of cervical length: a population-based prospective study. Ultrasound in Obstetrics and Gynecology: The Official Journal of the International Society of Ultrasound in Obstetrics and Gynecology. 2006 ;27(4):362-7.

(17) Romero R, Espinoza J, Gonçalves LF, Kusanovic JP, Friel L, Hassan S. The role of inflammation and infection in preterm birth. InSeminars in reproductive medicine 2007;25 (1): 021-039. Copyright $@ 2007$ by Thieme Publishers, Inc., 333 Seventh Avenue, New York, NY 10001, USA.

(18) Yuan M, Jordan F, McInnes IB, Harnett MM, Norman JE. Leukocytes are primed in peripheral blood for activation during term and preterm labour. Molecular human reproduction. $2009 \mathrm{Jul}$ 23;15(11):713-24

(19) Cicarelli LM, Perroni AG, Zugaib M, De Albuquerque PB, Campa A. Maternal and cord blood levels of serum amyloid A, C-reactive protein, tumor necrosis factor- $\alpha$, interleukin- $1 \beta$, and interleukin-8 during and after delivery. Mediators of inflammation. 2005;2005(2):96-100.

(20) Kim MA, Lee BS, Park YW, Seo K. Serum markers for prediction of spontaneous preterm delivery in preterm labour. European journal of clinical investigation. $2011 \mathrm{Jul} ; 41(7): 773-80$.

(21) Mubark AM, Zeiny LS, Sadiq AM. Neutrophil to lymphocyte ratio \& cervical length for prediction of spontaneous preterm delivery in threatened preterm labour. Al-Qadisiah Medical Journal. 2015;11(19):232-41.

(22) Oskovi Kaplan ZA, Ozgu-Erdinc AS. Prediction of Preterm Birth: Maternal Characteristics, Ultrasound Markers, and Biomarkers: An Updated Overview. Journal of pregnancy. 2018;2018.

(23) Fuchs IB, Henrich W, Osthues K, Dudenhausen JW. Sonographic cervical length in singleton pregnancies with intact membranes presenting with threatened preterm labor. Ultrasound in Obstetrics and Gynecology: The Official Journal of the International Society of Ultrasound in Obstetrics and Gynecology. 2004 Oct;24(5):554-7.

(24) Sotiriadis A, Papatheodorou S, Kavvadias A, Makrydimas G. Transvaginal cervical length measurement for prediction of preterm birth in women with threatened preterm labor: a meta-analysis. Ultrasound in Obstetrics and Gynecology: The Official Journal of the International Society of Ultrasound in Obstetrics and Gynecology. 2010 ;35(1):54-64.

(25) Hiersch L, Melamed N, Aviram A, Bardin R, Yogev Y, Ashwal E. Role of cervical length measurement for preterm delivery prediction in women with threatened preterm labor and cervical dilatation. Journal of Ultrasound in Medicine. 2016 ;35(12):2631-40.

Ali, A., Ibrahim, S., Ahmed, M., kareem, S. Prediction of Preterm Delivery In Pregnant Women With Threatened Preterm Labor Using Transvaginal Ultrasound And Neutrophils To Lymphocytes Ratio. Zagazig University Medical Journal, 2019; Jully. 2020 Volume 26 Issue 4 (556-565): -doi: 10.21608/zumj.2019.11376.1182 